\title{
The Reconstruction of Economic Law System Based on the Network Game Theory
}

\author{
Lv Yipin ${ }^{1, a}$ \\ ${ }^{1}$ Xinyang College of Agriculture and Forestry, Xinyang, Henan, China 464000 \\ a18234806@qq.com
}

Keywords: game theory, economic law system, reconstruction, cooperation

\begin{abstract}
An important manifestation of the modernity of economic law is that the legal subject is endowed with more initiatives. The implementation of economic law is no longer the traditional process where policies are made by policy makers on their own intention, or passively accepted by policy recepients. On the contrary, policy recepients can adjust their ways against policies accordingly, while policy makers must timely alter their economic policies according to the different responses of the policy recepients so as to better achieve their intended purpose. In this paper, a model is designed based on game theory. After the assumption is put forward, the optimal direct mechanism and the corresponding configuration scheme of the reconstruction of the economic law are obtained by making a solution and quilibrium analysis of the mode, which are extremely effective means of ensuring the effectiveness and efficiency of the operation of economic law.
\end{abstract}

\section{Introduction}

With the establishment of the market economy system in the world, the status of economic law is becoming more and more prominent. However, due to the different development level of economic law around the world, there are still disagreements on its theory study, including the discussion of the establishment of economic law system. The research results of the economic law system can not only be used to guide the standard in the teaching of theory, but also fill the gaps in the legislation, perfect the solution of the legal defects, and promote the correct interpretation and reasonable application of the legal norms, which ultimately promote the development of China's market economy. So, it is of great importance to build a perfect economic law system[1,2]. The independent department law status of the economic law has already been established, which also means that the economic law has its own unique adjustment object. One of the basic problems of the study of economic law theory is the establishment of the economic law subject system. So far, domestic scholars hold different opinions about the edit of the teaching material of economic law that is used for the subject. At present, there are some representative theories such as "national coordination theory" and its subject system, "national intervention theory" and its disciplinary system, "national regulation" and its disciplinary system, "vertical and horizontal theory" and its disciplinary system, "modulation of relationship" and its disciplinary system. The classification of these disciplines has laid a good foundation for the development of economic law theory, and it is certain that what the economic law adjusts is the specific economic relations.

An important manifestation of the modernity of economic law is that the legal subject is endowed with more initiative. The implementation of economic law is no longer the traditional process where policies are made by policy makers on their own intention, or passively accepted by policy recepients. On the contrary, policy recepients can adjust their ways against policies accordingly, while policy makers must timely alter their economic policies according to the different responses of the policy recepients so as to better achieve their intended purpose. In this continuous process of mutual response, there is considerable room generated for the game, which exists not only between the policy makers and policy recepients, but in the recepients as well. In this paper, through the analysis of the strategic choice of economic law subject under different conditions, the introduction of the game 
method in the economic law is proved to be of the reality and necessity to better promote its implementation.

\section{Game theory and game equilibrium}

No agreement has been reached about the exact definition of game theory. The 1994 Nobel Prize winner Harsanyi made the following definition ${ }^{[5]}$ : game theory is about the interaction of strategy. That is to say, the game theory is about the theory of rational behavior in society, in which the choice made by the participants about their own actions must be based on the judgment of how he will react to other people. It can be understood that the game theory is a theory of how people make decisions based on the behavior of each participant in a competitive environment. From this understanding, the following four elements should be considered, as shown in figure 1:



Figure 1 Four elements about game

After the rules of the game is established, the status of the participants are equal, and they must act strictly in accordance with the rules. In the game, participants may have different choice in the number and the content of the strategy, the number of their choice may be limited or be infinite. There must be an order in a game. If the order changes, though without any other changes, the game changes. There is need to make a provision for the benefit in a game; the benefit can be set as positive or negative, and it is the standard and basis for analyzing the game model.

Game theory assumes that the participants are rational and sensible; in all the strategies that can be choosed by the participant, he is independent and not subject to any form of coercion by any other person. In a typical structure of payment, the benefit made by the participant is not only related to his choice of strategy, but also a function of other people's choice. That is to say, the interests of the participants are interrelated and mutually restricted. Under the assumption that the participants pursue their own maximized benefits, the game theory studies the behavior of these rational individual choice. The "solution" of a game, known as the "equilibrium", is the most likely outcome of the game. Game equilibrium consists of the following elements, as shown in figure 2, the general equilibrium reflects the the relationship between the price and the demand of goods in the market or the equilibrium state. Though Nash equilibrium is made up of the individual optimal strategy, it does not mean that it is the result of an overall optimal. In the case of the conflict between the individual rationality and the collective rationality, the ultimate outcome resulted from people pursuing their benefit is a Nash equilibrium, which may be an adverse outcomes for all people. Therefore, Nash equilibrium, in essence, is a kind of non cooperative game. Bias Nash equilibrium is not a static equilibrium, but it can correctly predict the relationship between other participants and their own choices. On the optimal state of Pareto, changes have no effect on other's situation. In short, the Nash equilibrium is merely a kind of balance, not necessarily the best of Pareto, not necessarily the perfect ending. 
Cooperative game is defined according to non-cooperative game. If there is an agreement reached before the cooperation to ensure the implementation of the cooperation, it is the cooperative game; otherwise, it is the non-cooperative game. If an antagonistic non-cooperative game can be transformed into a non-antagonistic cooperative game, the yield is higher than that of confrontation. So cooperative game is a kind of method to configure the resources more effectively, and cooperative games are getting more and more attention. Cooperative game is a game in which the parties to achieve a mandatory and binding contract on the basis of the exchange of information. Cooperative game allows the parties to establish a cooperative awareness through negotiation and communication, and to establish the mechanism of mutual trust, restraint and commitment to achieve the optimal allocation of resources. The cooperative game theory emphasizes the team's rationality, efficiency and fairness, and eliminates the information asymmetry among participants through information exchange and bargaining. Cooperative game has the following characteristics:

(1)Sharing common interests;

(2)Necessary information exchange;

(3) Voluntary, equality and mutual benefit, the participants are able to share the benefits from the cooperative game;

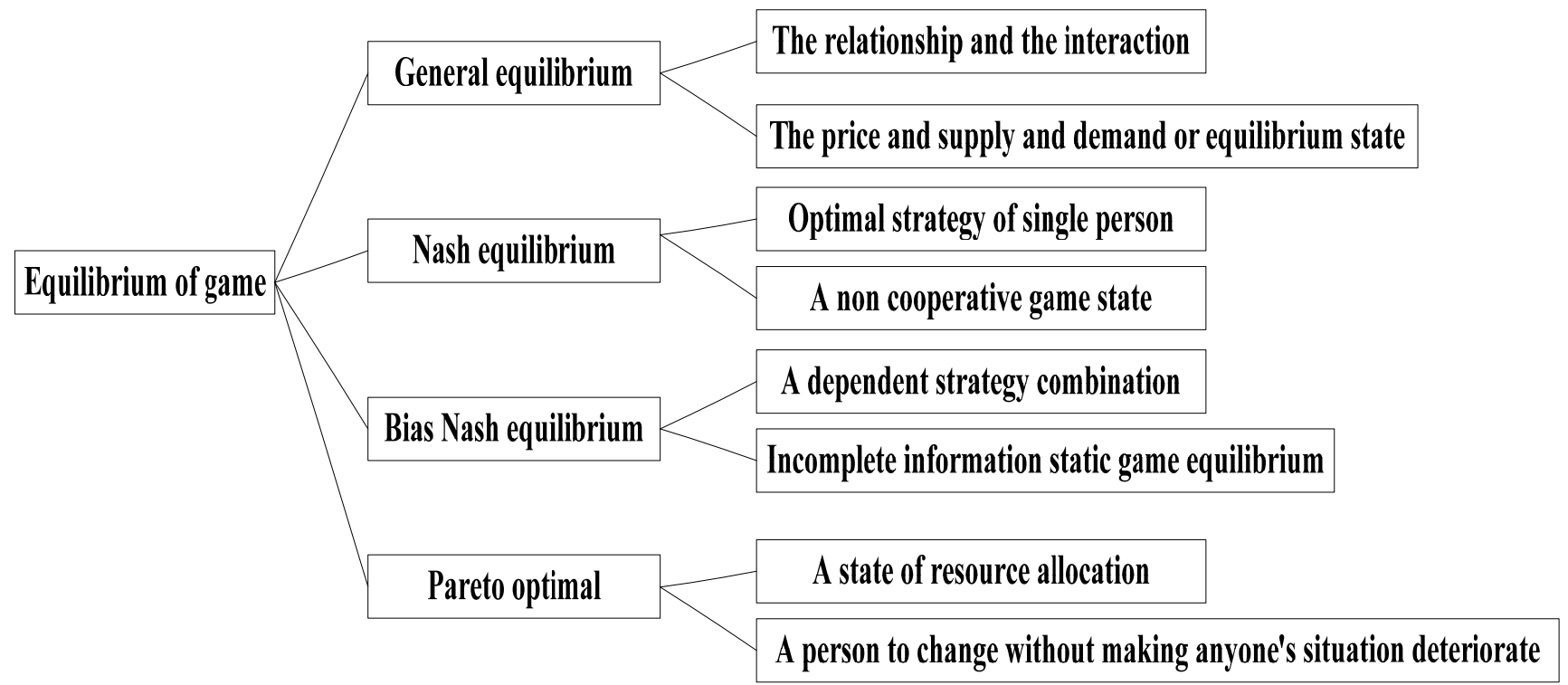

Figure 2 The expression of the game equilibrium

The difference between cooperative game and non cooperative game is shown in table 1.

Table 1 The differences between cooperative game and non cooperative game

\begin{tabular}{ccc}
\hline Contents & Cooperative game & Non cooperative game \\
\hline Achievable or not & Yes & Generally not \\
Binding agreement & Binding agreement & Binding agreement \\
Basic element & Joint action by the participants & $\begin{array}{c}\text { Possible action by individual } \\
\text { participant } \\
\text { Possible endogenous } \\
\text { cooperation }\end{array}$ \\
Standard expression & Exogenous cooperation & eoalitional一 form \\
& extensive - form & \\
\hline
\end{tabular}




\section{Game model and legal system construction}

With the development of social life, there are more and more unequal trade. The individual is weak and feeble in front of a huge economic group. The post industrial era is teemed with monopoly, and the nature market game has witnessed qualitative change, all of which can be embodied in the benefit of game:(A for the weak side of the transaction, $\mathrm{B}$ for the strong side).

Table 2 The modern model of game

\begin{tabular}{cccc}
\hline & Transaction & Negotiation & Non transaction \\
\hline Transaction & $(9,11)$ & $(5,15)$ & $(-5,0)$ \\
Negotiation & $(12,10)$ & $(4,13)$ & $(-5,0)$ \\
Non transaction & $(-5,0)$ & $(-5,-2)$ & $(-3,0)$ \\
\hline
\end{tabular}

1. In this new game, the foundation of the traditional civil law-- based on equality of subject of "Nash equilibrium", has all gone. The rights and obligation system that is formulated with extraordinarily painstaking efforts become useless! Because the unified standard of the civil law is easier said than done, unfairness may arise from reluctant implementation.

2. On the other hand, $\mathrm{B}$, the strong side of the transaction, has since possessed a strict advantage strategy -- "negotiation", that is to say, whatever strategy A chooses, B get the most benefit by choosing "negotiation". Becuase of its strong economic strength as negotiation capital, B doesn't dread that party A refuses to pay.

3. In the new round of the game, the insignificant combination of "cooperation and non cooperation" strategy becomes signifcant. Suppose that B is the subject that dominates the market, under the situation that "A chooses transaction while B doesn't", A fails to achieve its transaction demand due to having no choice; under the situation " $\mathrm{B}$ chooses transaction while A doesn't", although A can find other alternative, but has to pay a high price. At last, when there is no transaction between A and B, B's loss is far less than A.;

This is the most essential aspect of the modern economic environment. Many politicians, jurists, economists tried to standardize this kind of trading relationship "formal equality, substantial equivalence" , but fall into the stereotype of traditional law_ _et the rights and obligations for the economic subjects, so that these rules are becoming more and more complex, and there are no signs of stopping - this is the inevitable result of the socialization of civil law.

After the adjustment of the benefits of the two sides, there is a new round of "Nash equilibrium". Civil law has another object to adjust, and a new direction to regulate-guide the strategic combination of "negotiation-negotiation", in which all social groups are fully expressed in the interests of the demands, and the interests of the two parties and that of the whole society are realized through group supervision and group movement.

Table 3 The adjustment model of game

\begin{tabular}{cccc}
\hline & Transaction & Negotiation & Non transaction \\
\hline Transaction & $(9,11)$ & $(7,13)$ & $(-5,-5)$ \\
Negotiation & $(11,8)$ & $(10,10)$ & $(-5,-5)$ \\
Non transaction & $(-3,2)$ & $(-3,0)$ & $(-3,-5)$ \\
\hline
\end{tabular}

\section{The reconstruction of economic law system model based on the network game theory}

\section{Model hypothesis}

There is no doubt that economic law is to adjust the specific economic relations. The key point of the theory of using the economic law to adjust the object lies in how to identify economic relations regulated by the economic law, and how to describe it by using corresponding theory. First of all, the 
object is specified instead of being erratic. The object cannot be regarded as comprehensive, "a variety of social and economic relations" or "various economic relations", and even "many different kinds of social relations", instead, the range of the objects should be expanded to include social and economic relations that, in essence, are not regulated by the economic law. Secondly, the objects of the economic law are unique, and are different from the objects of other legal departments, and the relation between them cannot be crossed or overlapped. The decision environment faced by the reconstruction of the economic law is complex, and the following assumptions are made to facilitate the analysis:

(1) There are only three participants in the game: policy makers, market operators and consumers. Limited rationality refers to the ability of participants to have statistical analysis ability and the ability to judge the benefit resulting from using different strategies. But these participants are lack of predictive power, being in a state of ration and irration. Therefore, both sides of the game are limited.

(2) Behavior strategy: in the new round of the game, the insignificant combination of "cooperation and non cooperation" strategy becomes signifcant.

(3) Proportion of behavior strategies: in the initial stages of policy makers, market operators and consumers, if the probability of the decision maker taking regulation is $\mathrm{y}$, the probability of the decision maker not taking regulation is $1-\mathrm{y}$, the probability of market operators to accept the legal system is $\mathrm{X}$, the probability of the public not implementing the regulation is $1-\mathrm{Z}$.

\section{Model building}

The order of the game between the economic law system and legal social cooperation can be described as: The introduction of economic law is to put the process of the game into the rules of economic law system, so that the relevant subjects in the system of the game can compete fully with each other, and as a result, all the participants can be rewarded and punished accordingly. But not all these rules and regulations can achieve this purpose, only those that benefit the participants can be observed. The process of judging and compliance is not based on people's belief or fear about law, but on people maximizing their benefit. Game is to pursue the optimal strategy to solve problems by studying people's thoughts and beliefs.

Any law operation is a process to formulate the rules and laws related to the involved participants, a process for participants to observe the rules and laws, and a process to see if the expected return of the relevant parties can become true. From its social essence, the game theory is about the mutual competition and mutual dependence, etc. among subjects because of the limited resources, so it is safe to say the mutual influence and interaction between people can be regarded as the phenomenon of game or the behavior of the game. Society is composed of different groups of people, and the interaction between them constitutes a generalized game. The following information should be included in a standard game model: the participants' strategy ', the information and the benefit. The information about the benefit is the key reference value of the game for the participants to choose a certain strategy. The rational party of the game always choose the strategy that will enable himself to gain the most benefit.

The game can be expressed as following in a two level programming:

$$
\begin{gathered}
\max _{T} W(T, C)=\int_{T}^{T_{1}}[R-V(C, t)] d t \\
\text { s.t } \quad U(T, C)=\int_{0}^{T}[R-V(C, t)] d t-C \geq \bar{u} \\
\max _{C} U(T, C)=\int_{0}^{T}[R-V(C, t)] d t-C
\end{gathered}
$$

Where $\mathrm{T}_{1}$ represents the decision-making time, and $\bar{u}$ represents the maximum return balance of economic law. 


\section{Optimal strategy analysis}

As the term shows, the game theory is that the market economy provides a huge space for game and competition, and provides a myriad of alternative strategies. The development of the market is related to the interests of each subject, who, in order to maintain their own maximized benefits, has to cooperate and compromise with each other to realize the so called "win-win". However, this kind of cooperation and compromise are bulit on the constant competition and the choice of strategy, and finally shown as the cooperation and restriction between subjects. Thererfore, the author uses the game theory to analyze the behavior that may be applied by the subjects, based on which the author further analyzes the the possible competition and cooperation strategy between the subjects.

Optimal investment strategy:

$$
C=C_{\theta}=C(\theta, R)=[h(\theta)]^{\frac{\beta}{\beta-\alpha}} \bar{C}(R)
$$

The nature possessed is:

$$
\begin{gathered}
\frac{\partial C}{\partial \theta}>0, C_{o} \leq \bar{C}(R) \\
\frac{\partial C}{\partial R}>0
\end{gathered}
$$

$h(\theta)$ 和 $\overline{\mathrm{C}}(R)$ is defined rescpectively as:

$$
\begin{gathered}
h(\theta)=\frac{(\beta+1) \theta-\theta^{\beta+1}}{\beta} \\
\bar{C}(R)=k^{\frac{-1}{\beta-1}}\left(\frac{\alpha}{\beta+1}\right)^{\frac{\beta}{\beta-1}} R^{\frac{\beta+1}{\beta-1}}
\end{gathered}
$$

$\mathrm{R}$ is the benefit of economic law, and $\mathrm{C}$ is the result of the game of economic law; Concession period $\mathrm{T}$ is a part of the effective operation period $\mathrm{T} 1$; $\mathrm{T}$ is an incentive concession period, among which $\theta$ is an incentive factor. As for the parameters $\alpha, \beta$, they can be determined on the statistics obtained according to the past similar construction costs and operating maintenance costs through fitting method.

The formula for the calculation is as following:

$$
\begin{aligned}
& \frac{\partial U}{\partial C}=\int_{0}^{\theta T_{1}} \frac{\partial V}{\partial C} d t+\theta\left[R-V\left(C, \theta T_{1}(C)\right)\right] \frac{\partial T_{1}}{\partial C}-1 \\
& =\frac{\alpha\left[(\beta+1) \theta-\theta^{\beta+1}\right] R C^{-1} T_{1}(C)}{\beta(\beta+1)}-1 \\
& =\frac{\alpha h(\theta) k^{\frac{-1}{\beta}} R^{\frac{\beta+1}{\beta}} C^{\frac{\alpha-\beta}{\beta}}}{\beta+1}-1 \\
& \frac{\partial^{2} U}{\partial^{2} C}=\frac{\alpha(\alpha-\beta) h(\theta)}{\beta(\beta+1)} R^{\frac{\beta+1}{\beta}} C^{\frac{\alpha}{\beta}-2}
\end{aligned}
$$

Since $\frac{\partial h}{\partial h}=\frac{(\beta+1)\left(1-\theta^{\beta}\right)}{\beta}>0$, so $0=h(0)<h(\theta)<h(1)=1$, the formula of $(10)$ is zero. In order to obtain the optimal solution of equation (5), it can be determined by equation (9). With properties as follows:

$$
\frac{\partial C}{\partial \theta}=\frac{\beta}{\beta-\alpha} \bar{C}(R)[h(\theta)]^{\frac{\alpha}{\beta-\alpha}} \frac{\partial h}{\partial \theta}>0
$$




$$
\begin{gathered}
\frac{\partial C}{\partial R}=\frac{\beta+1}{\beta-\alpha}[h(\theta)]^{\frac{\alpha}{\beta-\alpha}} \bar{C}(R) R^{-1} \\
C_{\theta}=[h(\theta)]^{\frac{\beta}{\beta-\alpha}} \bar{C}(R) \leq \bar{C}(R), \theta \in(0,1)
\end{gathered}
$$

The coordination of market order and the orderly development of the economy cannot be formed by any kind of force alone. Under the condition of market economy, the variety of subjects and the diversity of interests determine that the harmony and coordination of market and economic order is the result of the coordination and struggle of the interests of all parties. But the policy makers who have the right to intervene in the market, and the policy recipients who should enjoy the right and seek economic interests in the market are the two sides in the game should be firstly analyzed.

\section{The analysis of the reconstruction of economic law system based on Game Theory}

The development of the market is related to the interests of each subject, who, in order to maintain their own maximized benefits, has to cooperate and compromise with each other to realize the so called "win-win". However, this kind of cooperation and compromise are bulit on the constant competition and the choice of strategy, and finally shown as the cooperation and restriction between subjects. Thererfore, the author uses the game theory to analyze the behavior that may be applied by the subjects, based on which the author further analyzes the possible competition and cooperation strategy between the subjects. The value of the relevant economic variables are as follows:

Table 4 Value of economic variable

\begin{tabular}{ccc}
\hline Variable name & Symbol & Numerical value \\
\hline Parameter 1 & $\mathrm{h}$ & 0.4 \\
Parameter 2 & $\alpha$, & 0.4 \\
Parameter 3 & $\beta$, & 0.6 \\
Benefit effect of the economic law & $\mathrm{V}(\mathrm{C}, \mathrm{t})$ & $V(C, t)=0.4 C^{-0.4} t^{0.6}$ \\
Game effect of the economic law & $\mathrm{R}$ & 0.1 亿 \\
\hline
\end{tabular}

According to the above proposition, the optimal incentive coefficient of concession period can be calculated by numerical simulation. The method is shown in Figure 3:



Figure 3 Optimal incentive effect

Similarly, the change can be reflected by the use of numerical analysis methods, as shown in figure 4 and figure 5. 


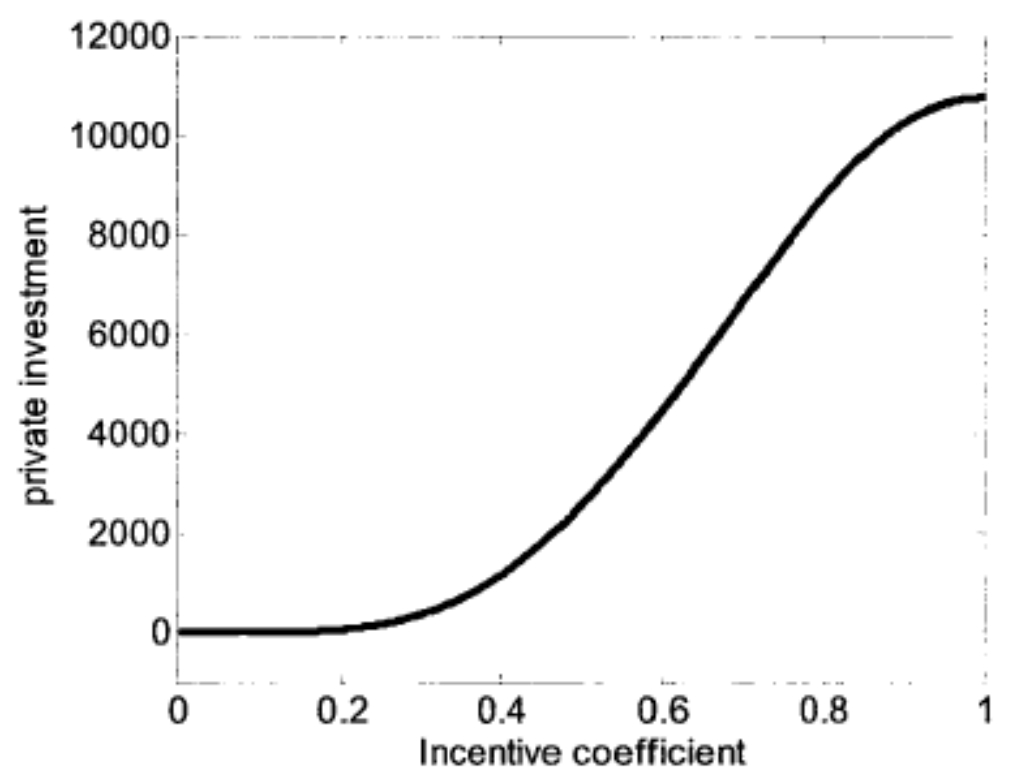

Figure 4 Game Analysis between policy makers and policy recipients

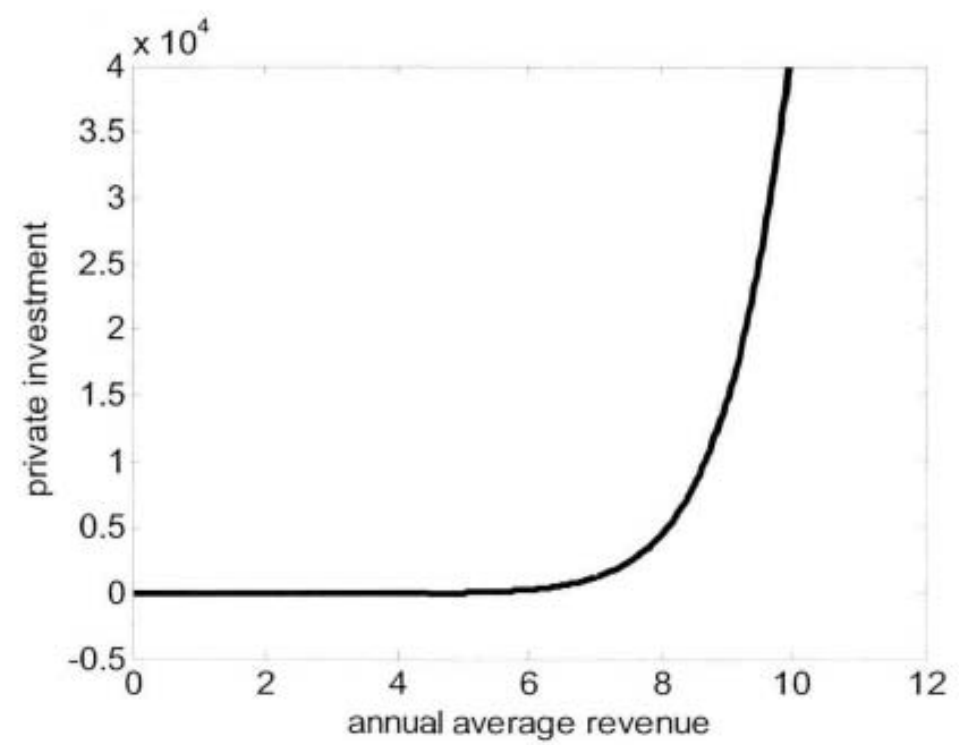

Figure 5 The result of the game among the operators in the policy recipients

\section{Reconstruction of economic law based on Game Theory}

The game theory is used to analyze the behavior that may be applied by the subjects, based on which the possible competition and cooperation strategy between the subjects are further analyzed.

(1) Game Analysis between policy makers and policy recipients

The policy recipient, on the other side of the game, may apply different strategies due to his status. For consumers, they dont want to pay high taxes for the realization of the public interests. Pursuing their own interests, market operators don't concern about whether the public interest can be realized. To pay more taxes for the realization of public interest is contrary to their own pursuit. In addition, for the market operators, their object is simple and clear, that is the realization of the maximization of interests. So, to achieve this goal, the most favorable strategy for the operators to apply is to eliminate other competitors and realize the monopoly of the market, which will help them obtain the best and even the only trading opportunities, thus obtaining the best interests. But this strategy is undoubtedly contrary to the pursuit of policy makers and consumers. As a result, The antagonistic relations of competition is formed, and is undoubtedly negated by the law.

In order to achieve their goals, governments have a positive and indirect interference in the market environment. In addition, taking the advantage of their funds and information, together with the need 
of the development of the country and society, governments will have a macro control and micro regulation over their markets. Blindness and arbitrariness of the market are corrected by providing some mandatory guidance to the market. To prevent the irrational and unfair competition and restore the orderly operation of the economy, irregularities in the market should be corrected and punished. For consumers, the policy recepients, a benign and fully competitive market is beneficial to the realization of their own interests. They are the beneficiary for the realization of public interest. Therefore, in this view, the strategy applied is usually the same as the policy makers. For the operators, the optimal strategy for their own benefits can not be approved by the law. So, only by using the good external environment provided by the state or government, and improve technology, improve product quality, etc., can the operators obtain the largest trading opportunities and realize their own interests within the legal framework. At the same time, the operator needs to restrain their own exceeded desire for interests, and undertake certain social responsibilities to get better reputation and visibility according to the need of the society, which will play a very important role in the realization of their own interests. In this way, there will be considerable cooperation and coordination between policy makers and recipients.

(2) The game between the operators in the policy recipients

The existence of operators and the differences between their own economic interests determine that there must be competition among the operators, which results in the inevitable friction and conflict among operators in the pursuit of their own maximized interests. This is usually expressed as unfair competition, such as "invasion of trade secrets" and intellectual property "monopoly, etc.. Generally speaking, in the market competition, operators with larger scale tend to hide their advanced technological secrets out of commercial purpose, or benefit directly from these technologies by regarding them as their own intellectual property rights. In addition, due to their stronger control over the market than smaller operators, the larger operators tend to dominate trading opportunities in the market by monopoly. Small scale operators, in order to save their cost in research and development, are more inclined to acquire advanced technology by means of stealing. At the same time, in order to get more trading opportunities, they are also more inclined to take unfair means to reduce their competitors' opportunity. This is the game full of antagonistic competition among the operators.

Only when operators cooperate with each other in raw materials procurement, sales, and logistics, can they effectively provide the society with their products. The operator's rival in the economic law is usually the government departments that regulate economy. So only when all the operators cooperate with each other, can they realy have control and restraint over government's power.

(3) Game Analysis between operators and consumers in the policy recipients

Between the operators and the vast number of consumers, operators, in order to pursue the maximization of their own interests, will inevitably infringe on the interests of consumers in the short term. Accordingly, consumers, in order to protect their own interests, will take the corresponding strategies, such as organizing movements to protect their own rights, or taking prosecution, etc.. Since consumers prefer those goods with better quality and lower price, it is more likely for the operators to get more trading opportunities if they respect consumers' preference. Accordingly, consumers will expand the operator's reputation by word of mouth, as a result the win-win situation can be achieved.

\section{References}

[1] Wang Jin-lin \& Chen Nai-xin,.New Exploration on the Problem of Economic Law System, Journal of Changsha University, Vol 6,2005p23..

[2] Chen Nai-xin \& Xia Yuan-hang, New Exploration on the Construction of Scientific Economic Law.Journal of Xiangtan University, Vol 1,2009, p 93.

[3] Huang Jian \& Yang Qin,.Exploration on the Reconstruction of Economic Law System,Journal of Hubei Adult Education Institute,Vol 1(19),2013,p 157-159..

[4] Chen An as the editor in chief,. The Forum on the International Economic Law (Vol. 7) Law Press.,2003 p32-34. 
[5] Yang Zi-huan,Economic Las,,Beijing, Beijing University Press,2007 ,p 23-26.

[6] Li Zhang-xuan-zi,.Discussion on the Adjustment of Economic Law to the Degree of Enterprise.Jiangxi Finance and Economics University , 2008, p 48-49.

[7] Zhang Shou-wen,Discussion on the Coordination of the Economic Law -- The Enlightenment of the National Coordination Theory, Vol 1,2011, p33-43.

[8] Lian Jie \& Chen Nai-xin.The adjustment of Economic Law in the Perspective of Legal Time Theory.Journal of Nanhua University, Vol 2,2008,p 86-97.

[9] Li Chang-lin as the editor in chief, Economic Jurisprudence, Law Press, 2007, p 22-26. 